highly fluorescent substances, electronic energy may pass from molecule to molecule before radiation of fluorescence occurs. The distance over which such transfers take place may be as large as $50 \mathrm{~A}$. or more, so that the effect may be observed in solutions of concentration $10^{-3}-10^{-2} \mathrm{M}$. Resonanee transfer is of importance in the study of photosynthesis by chlorophyll in plants and in the use of fluorescent substances as scintillation counters for radioactive rays. After long hiding its light under a bushel, fluorescence is now being brought out into the daylight, and rapid advances in practice and theory may be confidently predicted.

E. J. BOWEN

\section{TEXT-BOOKS OF ORGANIC CHEMISTRY}

\section{Organic Chemistry}

By Louis F. Fieser and Mary Fieser. Second edition. Pp. $x v+1125$. (Boston, Mass. : D. C. Heath and Co. ; London : George G. Harrap and Co., Ltd., 1950.) 7.50 dollars; $42 s$.

Organic Chemistry

By Dr. A. F. Holleman. Revised by Prof. J. B. Wibaut. Translated from the sixteenth Dutch edition by Dr. Samuel Coffey. Pp. xiv +660 . (New York and Amsterdam: Elsevier Publishing Co., Inc.; London: Cleaver Hume Press, Ltd., 1951.) $55 s$.

\section{Organic Chemistry}

By Dr. I. L. Finar. Pp. xv +696. (London, New York and Toronto : Longmans, Green and Co., Ltd., 1951.) $40 s$. net.

MOST organic chemists have their own ideas 1 concerning the perfect text-book for their subject, and a surprisingly large number possess the energy to bring their conceptions to fruition. As a result, students at all levels have a wide choice of guide to explore what Wöhler termed the "monstrous and boundless thicket" of organic chemistry.

The popularity of the first edition (1944) of the text-book by Prof. and Mrs. L. F. Fieser was due not only to its wide scope and up-to-date treatment but also to the clarity, readability and occasional humour of its exposition. These characteristics are retained in the new edition, which incorporates the significant advances of the past six years. Two major omissions in the first edition have been remedied with the introduction of chapters on reaction mechanisms (a triumph of well-written condensation) and on heterocyclic compounds. Space for these inclusions has been found by substantial pruning of previously over-written chapters (for example, steroids and quinones) and by adaptations of the format. Only one misprint could be detected, and the printing and binding are admirable. The pre-eminent usefulness of this book for all classes of student arises as much from its enthusiasm and feeling for the subject as from the attributes described above.

Roughly comparable in scope is the text-book of Prof. A. F. Holleman, revised and adapted by Prof. J. B. Wibaut; but the treatment tends to be oldfashioned and rather disjointed. Discussion of the usual homologous series is carried through with painstaking thoroughness; the more advanced topics are, however, treated much more cursorily. 'I'here are some startling omissions. The enormous advances in the separation of the constituents of protein hydrolysates are dismissed in four lines with no reference to paper chromatography. Again, in the section dealing with benzenoid substitution the concepts of inductive effect, mesomeric effect and hyperconjugation are not even mentioned; there is a similar lack of reference throughout to modern ideas concerning reaction mechanisms. It would not be inaccurate to classify the work as a present-day representative of an older type of text-book. The translation on the whole reads smoothly, although it is hoped that, in any future edition, the monstrosity "higherhydric" will be elimirated. The printing and binding are good.

The content of Dr. I. L. Finar's book is deliberately restricted to the basic groundwork of the subject and does not deal with topics such as the more complex natural products. Although thus limited in scope, the treatment is both complete and modern with full mention of the unifying physico-organic concepts. In particular, this seems to be the first organic chemistry text-book to include an elementary exposition on molecular orbitals, and recently introduced reagents and techniques (for example, lithium aluminium hydride) are discussed. The style is clear and readable, and the book can be recommended as providing a sound foundation for more advanced study. R. A. RaphaEL

\section{TEMPORAL INTEGRATION AS A CLUE TO MIND}

The Organization of Behavior

A Neuropsychological Theory. By D. O. Hebb. (Wiley Books in Clinical Psychology.) Pp. xix +335 . (New York : John Wiley and Sons, Inc. ; London: Chapman and Hall, Ltd., 1949.) 32s. net.

CINCE its publication, Prof. D. O. Hebb's book $S$ has been widely and sympathetically discussed, and has won a place among the more notable contributions to current theory in physiological psychology. Its author was unusually well equipped for the ambitious task he undertook, namely, to formulate a theory of behaviour embodying recent developments in the neurophysiology of the brain as well as in experimental psychology itself.

Dr. Hebb allies himself at the outset with those theorists in psychology, sometimes called 'reductionists', who have no hesitation in introducing neurophysiological concepts to explain human behaviour. The 'non-reductionists' take the view that this cannot be done without injury to the psychological facts. Dr. Hebb attempts to safeguard himself against criticism from this direction by not denying or ignoring the complex facts of behaviour. He does not deal with mind by reducing it to the level of what is now known about the body; he rather suggests highly complicated forms of neural interaction which may help to explain what is now known about mind. Here his main contribution lies in his conception of temporal integration in cerebral activity. This conception has received strong support from the independent work of H. F. Harlow on 'learning sets' and of $H$. O. Mowrer on the persistence of selfdefeating behaviour.

The theoretical gap which Dr. Hebb proposes to fill he attributes to the failure of neurophysiology to explain the events that occur in cortical transmission, that is, during the interval between the arrival of an excitation at a sensory area and its departure from 